\title{
CARACTERIZAÇÃO DA ARQUITETURA INTERNA DAS BACIAS DO VALE DO CARIRI (NE DO BRASIL) COM BASE EM MODELAGEM GRAVIMÉTRICA 3-D
}

\begin{abstract}
D. L. de Castro ${ }^{1} \&$ R. M. G. Castelo Branco ${ }^{2}$
A região do Vale do Cariri, entre os estados do Ceará, Paraíba e Pernambuco, engloba as principais bacias interiores cretácicas do Nordeste do Brasil (bacias do Araripe, Rio do Peixe, Iguatu e Lima Campos, entre outras). Atualmente esta região apresenta uma considerável cobertura de estações gravimétricas, pertencente aos acervos de dados geofísicos do Instituto Brasileiro de Geografia e Estatística (IBGE) e do Observatório Nacional (ON). Com a finalidade de melhorar a distribuição de estações gravimétricas atualmente disponíveis, o Laboratório de Geofísica de Prospecção e Sensoriamento Remoto (LGPSR / UFC) executou um levantamento complementar em parceira com a Divisão de Geociências do IBGE, que permitiu uma modelagem gravimétrica tridimensional destas bacias rifte. Um procedimento de interpretação iterativa 3-D foi aplicado às anomalias gravimétricas da região do Vale do Cariri. Os modelos geofísicos resultantes forneceram estimativas aproximadas para o arcabouço geométrico das coberturas sedimentares, muito condizentes com informações de furos de sondagem e modelagens geofísicas prévias. A arquitetura interna das bacias em apreço, reveladas pelo processo interpretativo, confirma o forte controle estrutural exercido pelas zonas de fraqueza crustais preexistentes. Tal fato reforça a hipótese de reativação das extensas zonas de cisalhamento neoproterozóicas durante a implantação do rifteamento mesozóico responsável pela ruptura do paleo-continente Gonduana, com a separação América do Sul - África e abertura do Oceano Atlântico.
\end{abstract}

Palavras-chave: Modelagem gravimétrica 3-D; Bacias rifte cretácicas; Vale do Cariri; Nordeste do Brasil.

CHARACTERIZATION OF THE INTERNAL ARCHITECTURE OF THE CARIRI VALLEY RIFT BASINS, BASED ON 3D GRAVITY MODELING-An inversion method for three-dimensional modeling of gravity anomalies has been applied in the main intracratonic basins of Northeastern Brazil. These NE trending sedimentary basins of Cretaceous age are located in the Cariri Valley, in Ceará, Paraíba, and Pernambuco states, NE Brazil. The gravity stations database was obtained by several geophysical surveys carried out by Brazilian universities and geological government agencies. A complementary gravity survey was conducted by the "Laboratório de Geofísica de Prospecção e Sensoriamento Remoto” (LGPSR) of Ceará State University and "Instituto Brasileiro de Geografia e Estatística" (IBGE) to improve the distribution of gravity stations in the study area. The iterative interpretation technique was applied to the gravity anomalies of the Cariri Valley, which resulted in reliable estimates of the internal geometry of the rift basins. The gravity models indicate a strong structural control of pre-existing upper crustal weakness zones in the development of the graben architecture of the basins. This provides additional arguments to the hypothesis of extensive Neoproterozoic shear zone reactivation during the Mesozoic rifting process, whose evolution resulted in the South America - Africa separation and the opening of the Atlantic Ocean.

Key words: Gravity Modeling; Cretaceous Rift Basins; Cariri Valley; Northeastern Brazil.

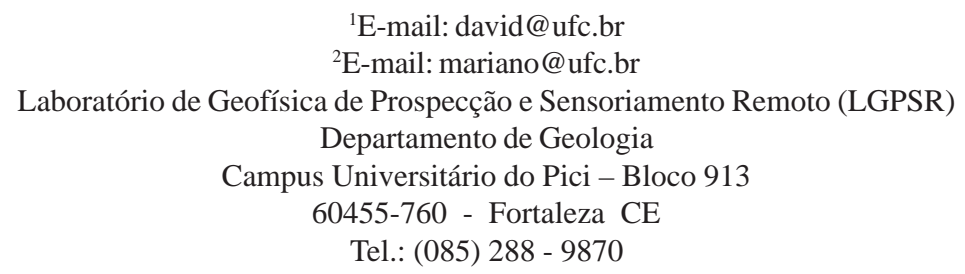




\section{INTRODUÇÃO}

A região do Vale do Cariri, na porção central do Nordeste Brasileiro, é caracterizada pela presença de uma série de bacias sedimentares interiores de pequeno a médio porte (Araripe, Rio do Peixe, Iguatu e Icó, entre outras). O embasamento cristalino é formado por diferentes domínios estruturais pertencentes à Província Borborema. Estes domínios encontram-se intensamente deformados e dominados por zonas de cisalhamento de idades neoproterozóicas. A reativação Eocretácica destas zonas durante o processo de rifteamento intracontinental mesozóico, associado à abertura e formação do Atlântico Sul, condicionou a estruturação interna das bacias intracratônicas. Neste contexto, tais bacias rifte registram em seu arcabouço geométrico a relação entre os esforços distensionais cretácicos e as reativações das zonas de fraqueza crustais preexistentes, que definem a trama estrutural atual da Província Borborema.

Os estudos geológicos na região das bacias rifte datam do início do século, visando o conhecimento dos recursos naturais do Nordeste. Porém, só a partir da década de 60 houve um maior interesse no reconhecimento hidrogeológico regional para fins de combate às secas, resultando em inúmeros trabalhos sobre a estratigrafia, potencial hidrogeológico e geotectônica regional. Os anos 80 se iniciaram com a aplicação de métodos geofísicos, inseridos na crescente pesquisa de petróleo nas bacias interiores do Nordeste. Os principais métodos utilizados foram a gravimetria, a magnetometria e a sísmica de reflexão. Os levantamentos gravimétricos e magnetométricos na Bacia do Araripe foram empreendidos por Oliveira (1983) e Rand \& Manso (1984) e na Bacia do Rio do Peixe por Rand (1984). Um consórcio das empresas nacionais levantaram 10 linhas de sísmica de reflexão na Bacia do Araripe, em regime de contrato de risco com a Petrobrás (Ghignone et al., 1986). Mais recentemente, Bedregal et al. (1992) realizaram um detalhado levantamento gravimétrico na Bacia de Iguatu.

Apesar do avançado estágio atual do conhecimento da configuração estrutural das bacias rifte, modelagens geofísicas tridimensionais que revelem seu arcabouço geométrico ainda são escassos na região. Os trabalhos de Rand (1984) e Rand \& Manso (1984) apresentam apenas modelos bidimensionais realizados em poucos cortes regionais nas bacias do Araripe e Rio do Peixe. As seções sísmicas revelam com detalhes as seqüências sismo-estratigráficas da Bacia do Araripe, porém não propiciam uma visão 3-D para toda a extensão da bacia. Bedregal et al. (1992) apresentam um modelo tridimensional para a Bacia de Iguatu, sem contudo estender suas conclusões as demais bacias interiores do Nordeste. Neste sentido, a presente modelagem gravimétrica tem como objetivo obter estimativas para a arquitetura geral deste conjunto de bacias e com isso fornecer subsídios adicionais ao conhecimento de sua evolução tectônica fanerozóica no contexto da trama estrutural precambriana.

A região do Vale do Cariri já apresentava uma considerável cobertura de dados gravimétricos, pertencentes aos acervos de dados geofísicos do Instituto Brasileiro de Geografia e Estatística (IBGE) e do Observatório Nacional. A distribuição espacial das observações gravimétricas foi complementada por uma campanha geofísica realizada pelo Laboratório de Geofísica de Prospecção e Sensoriamento Remoto (LGPSR) da Universidade Federal do Ceará (UFC) em parceria com a Divisão de Geociências do IBGE. Ao conjunto de dados gravimétricos foi aplicado um procedimento iterativo, que forneceu modelos tridimensionais para as bacias interiores. A partir de informações independentes (modelagens geofísicas, sísmica de reflexão e furos de sondagem), obtidas em trabalhos prévios, foi possível vincular, de forma indireta, as soluções da modelagem gravimétrica a resultados mais plausíveis sob o ponto de vista do conhecimento geológico local. Por fim, a partir do arranjo estrutural em profundidade revelado pela modelagem gravimétrica, realizou-se uma análise das implicações tectono-sedimentares do controle estrutural das extensas zonas de cisalhamento neoproterozóicas na evolução geotectônica das bacias rifte do Vale do Cariri.

\section{BACIAS RIFTE DO VALE DO CARIRI}

Chang et al. (1992) reconheceram três megaseqüências estratigráficas sin-rifte continentais (fases sin-rifte I, II e III), pertencentes ao segmento norte do sistema rifte do Atlântico Sul. As sequiências sin-rifte foram desenvolvidas durante a separação América do Sul - África, no Mesozóico Superior. O sistema rifte do Nordeste do Brasil sofreu uma maior influência das duas últimas fases sin-rifte, quando ocorreram os principais esforços de estiramento e ruptura crustal com a reativação das extensas zonas de cisalhamento proterozóicas e uma expressiva sedimentação nas bacias costeiras e interiores (Matos, 1992).

A segunda fase sin-rifte (Neocomiano Barremiano Inferior) foi marcada por uma intensa deformação distensional com estiramento crustal de orientação NW-SE, que ocasionou a formação de uma 
seqüência de bacias sedimentares intracratônicas, orientadas segundo uma direção principal NE-SW, denominada Trend Cariri - Potiguar por Matos (1992). Tais bacias são caracterizadas por uma geometria de meio-graben, separadas por altos do embasamento, falhas de transferências e/ou zonas de acomodação. O eixo principal do Trend Cariri-Potiguar coincide com uma concentração de sequiências de faixas supracrustais geradas e/ou retrabalhadas durante o Ciclo Brasiliano (faixas Cachoeirinha-Salgueiro, Orós, Jaguaribe, Extremo Oeste do Rio Grande do Norte e Seridó), aflorantes na porção central da Província Borborema (Jardim de Sá, 1994; Sá et al., 1995). Consequentemente, o processo de rifteamento na crosta superior teria sido influenciado, sobremaneira, por zonas de fraqueza proterozóicas (Matos, 1987). Através da inversão de anomalias gravimétricas regionais, Castro \& Medeiros (1997) identificaram uma zona de afinamento crustal de direção geral NE-SW, concordante com o eixo de deformação distensional e subsidência tectônica que culminaram com a implantação das bacias do Trend Cariri - Potiguar.

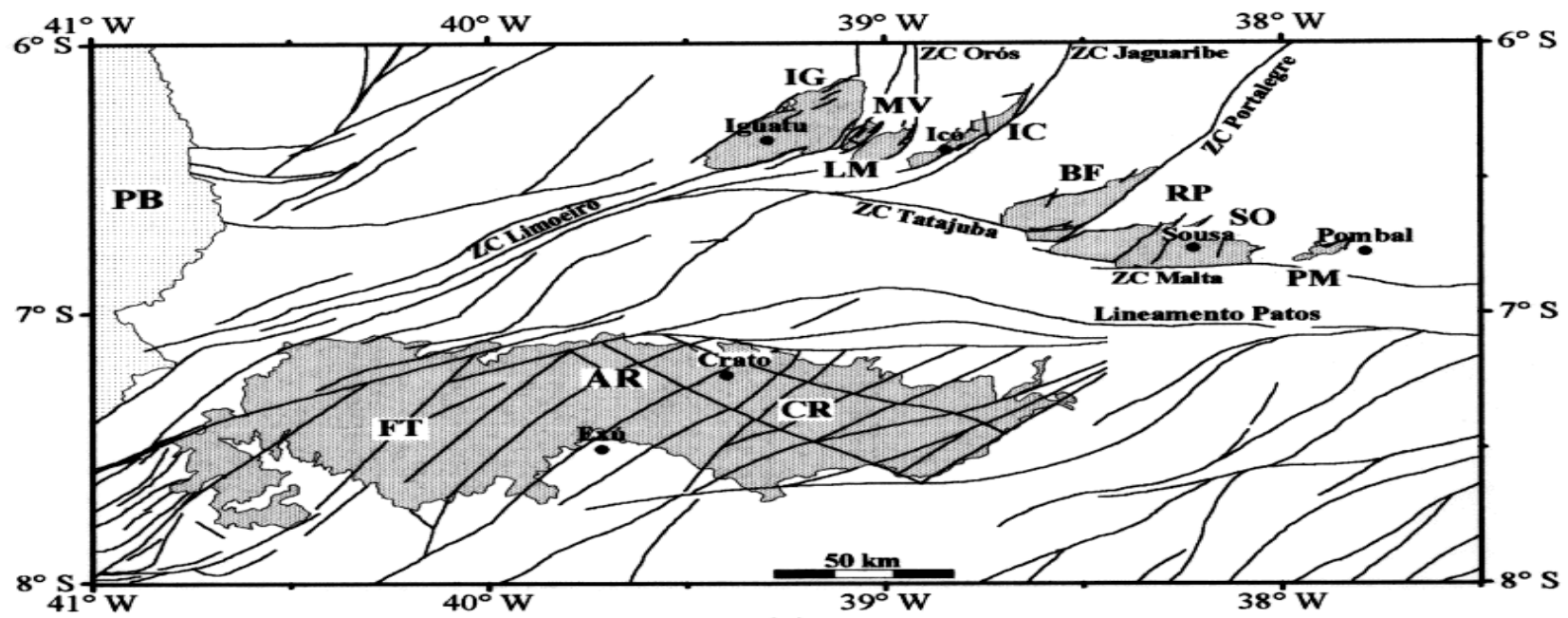

(a)

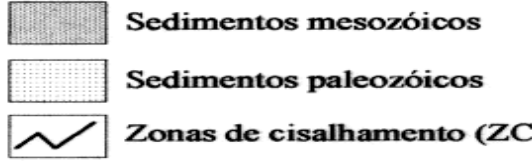

\section{BACIAS SEDIMENTARES}
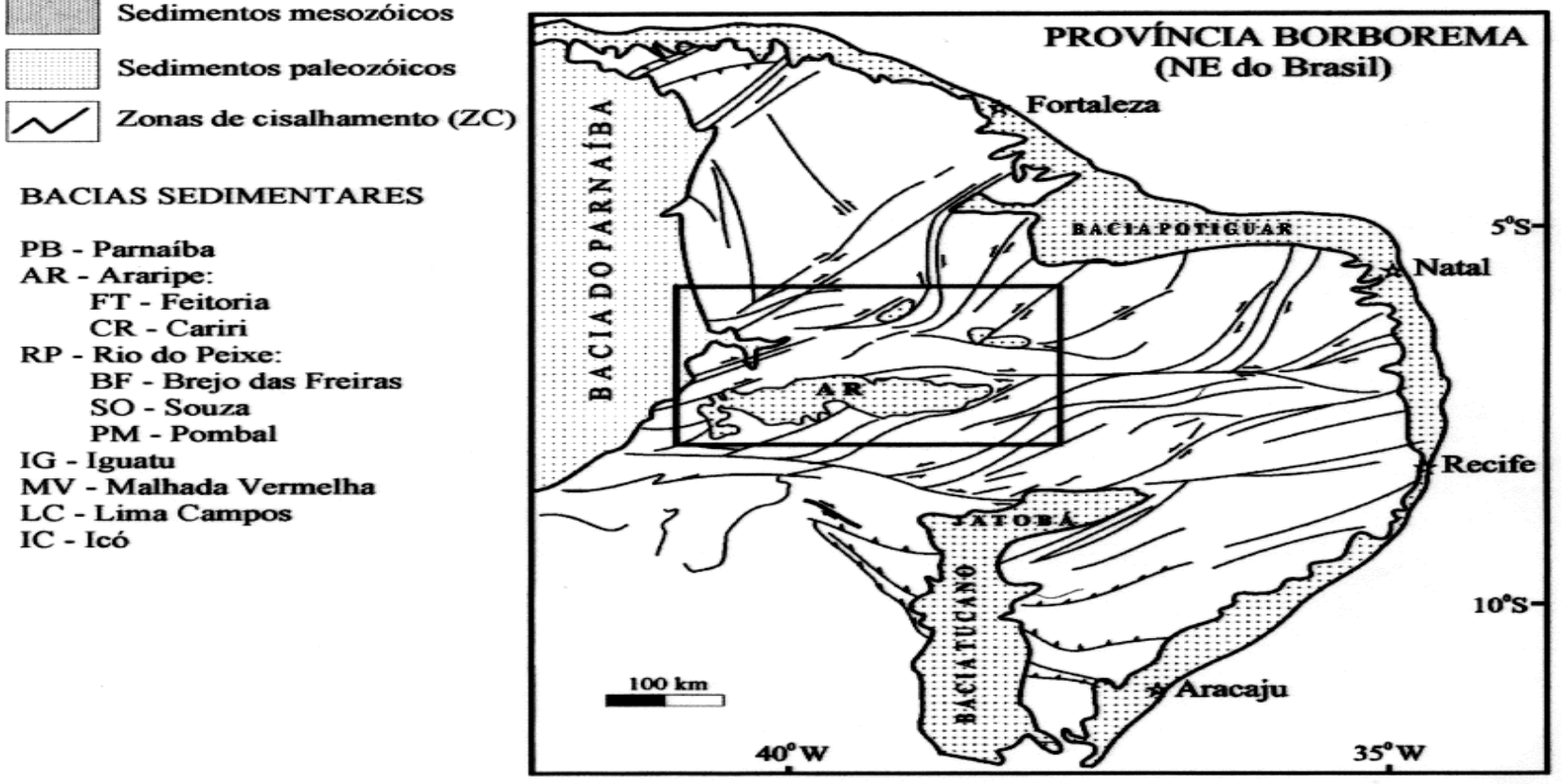

(b)

Figura 1- Esboço geológico simplificado (a) e localização geográfica das bacias rifte do Vale do Cariri no contexto da Província Borborema (b). Adaptado dos mapas geológicos do Projeto Rio Jaguaribe (Brasil. MME - DNPM, 1979), do Projeto Radambrasil - Folha Jaguaribe - Natal (Brasil. MME - DNPM, 1981), Jardim de Sá (1994) e Ponte \& Ponte Filho (1996).

Figure 1-Geological sketch map of the rift basins in Cariri Valley (a) and the location of the studied area in the frame of the Borborema Province (b), adapted from the Rio Jaguaribe Project (Brasil. MME - DNPM, 1979), Radambrasil Project Folha Jaguaribe - Natal (Brasil. MME - DNPM, 1981), Jardim de Sá (1994) and Ponte \& Ponte Filho (1996). 
As bacias rifte do Vale do Cariri (Fig. 1), também denominadas bacias interiores mesozóicas do Nordeste, são representadas pelas bacias do Araripe, Rio do Peixe, Iguatu, Malhada Vermelha, Lima Campos e Icó, entre outras de menor porte, distribuídas entre os estados do Ceará, Pernambuco e Paraíba. Este agrupamento de coberturas sedimentares de pequeno a médio porte representa os resquícios de uma bacia mesozóica pretérita de dimensões regionais, que sofreu uma intensa ação erosiva (Ponte et al., 1991). Porém, para não se adentrar em conceitos terminológicos mais rígidos, os pacotes sedimentares modelados no presente trabalho serão tratados genericamente de bacias.

Situada na Chapada do Araripe e na porção sul do Vale do Cariri (Fig. 1a), a Bacia do Araripe estendese por uma área de cerca de $8.000 \mathrm{~km}^{2}$ (Ponte \& Ponte Filho, 1996). A deposição do seu pacote sedimentar esteve vinculada aos dois estágios iniciais de rifteamento (fases sin-rifte I e II). Sua seqüência basal de idade jurássica repousa sobre um embasamento constituído por faixas dobradas e maciços proterozóicos do sistema de dobramentos Piancó-Alta Brígida (Brito Neves, 1990) e/ou sedimentos devonianos associados à Bacia do Parnaíba (Ghignone et al., 1986). A seqüência jurássica (pré-rifte) da Bacia do Araripe representa a expressão mais setentrional da sedimentação da fase sin-rifte I. A seqüência sin-rifte sobrejacente, de idade neocomiana, tem origem fluvio-deltaica relacionada à fase rifte posterior. A sequiência superior é formada por uma cobertura de estratos tabulares, subhorizontais, de idade mesocretácicas, que constituem o Grupo Araripe. Esta sequiência pós-rifte não é detectada nas bacias do Rio do Peixe e Iguatu. Campanha (1987) identificou espessuras próximas a $1.500 \mathrm{~m}$ para a coluna lito-estratigráfica da Bacia do Araripe, através do poço 2-AP-1-CE nas proximidades da cidade de Araripe (CE).

A reativação das zonas de fraqueza associadas ao lineamento Patos, com orientação E-W, além de falhas normais NE-SW, controlou a compartimentação estrutural do embasamento, imprimindo à bacia uma forma alongada de direção E-W com suave basculamento para SW na sua porção oeste. O compartimento estrutural de estilo rifte resulta do tectonismo tafrogênico eocretácico, denominado de Reativação Vealdeniana (Almeida, 1967). Com base em aspectos geológicos de superfície e em dados de gravimetria e sísmica de reflexão, Ponte \& Ponte Filho (1996) identificaram duas sub-bacias: Feitoria (a oeste) e Cariri (a leste), separadas por um alto estrutural, interposto, denominado "Horst de Dom Leme".

Já a Bacia do Rio do Peixe situa-se a NE da bacia do Araripe (Fig. 1), sendo dividida nas sub-bacias Brejo das Freiras, Sousa e Pombal. A geometria interna da bacia é formada por um conjunto de meio-grabens assimétricos (Françolin et al., 1994). O controle do arcabouço estrutural destas sub-bacias foi exercido pelo arranjo dos elementos tectônicos preexistentes, tais como as falhas de Malta (E-W) e Portalegre (NE-SW). Sedimentos clásticos intracontinentais preencheram esta bacia rifte durante o Neocomiano (Matos, 1992). Arai et al. (1989) não observaram evidências da sedimentação jurássica presente na Bacia do Araripe, denotando o caráter relativamente mais recente da Bacia do Rio do Peixe (fase sin-rifte II - Cretáceo Inferior).

Mais a NW, encontra-se uma nova série de bacias rasas do tipo meio-graben, caracterizadas por seus flancos NW com mergulho suave e SE com mergulho forte, bem como por um nítido controle estrutural exercido por zonas de cisalhamento proterozóicas NE-SW (Limoeiro, Orós e Jaguaribe) (Bedregal et al., 1992). De NW para SE alinham-se as bacias de Iguatu, Malhada Vermelha, Lima Campos e Icó, posicionadas nas inflexões para NE das faixas orogênicas Orós e Jaguaribe (Fig. 1a). O pacote sedimentar destas bacias também é formado por clásticos intracontinentais típicos como arenitos, conglomerados, siltitos, folhelhos e ritmitos (Ghignone et al., 1986). Segundo estes autores, o conteúdo fossilífero indica idades variando do Cretáceo Inferior ao Neocomiano, para as seqüências sedimentares das referidas bacias rifte.

\section{PROCESSAMENTO DOS DADOS GRAVIMÉTRICOS}

O conjunto de dados utilizados para a modelagem 3-D das bacias rifte do Vale do Cariri faz parte dos acervos de estações gravimétricas pertencentes ao Departamento de Geofísica do Observatório Nacional $(\mathrm{CNPq} / \mathrm{ON})$ e à Divisão de Geociências do Instituto Brasileiro de Geografia e Estatística (DIGEO - Fortaleza/IBGE), que foram gentilmente cedidos ao Laboratório de Geofísica de Prospecção e Sensoriamento Remoto da Universidade Federal do Ceará (LGPSR/UFC). As medidas gravimétricas oriundas do $\mathrm{CNPq} / \mathrm{ON}$ foram levantadas por diferentes projetos de pesquisa e convênios desenvolvidos por universidades (UFRN, IAG/USP, UFPE) e por empresas e órgãos públicos (CPRM, Petrobrás, ON, IBGE). Os procedimentos usuais de reduções gravimétricas (as correções dos efeitos de deriva e maré, latitude, ar-livre e Bouguer) foram aplicados previamente aos 
dados coletados, que encontram-se referenciados à Rede de Padronização Gravimétrica Internacional de 1971 (IGSN71).

Com o objetivo de aumentar a cobertura das 1.775 estações gravimétricas já existentes, foi realizado um levantamento complementar pelo LGPSR/UFC em parceria com a DIGEO/IBGE. Assim, 140 estações gravimétricas foram medidas com um gravímetro Lacoste-Romberg modelo $\mathrm{G}$, com precisão de $\pm 0,01$ mgal. Utilizou-se um espaçamento médio entre as estações de cerca de $5 \mathrm{~km}$ para a Bacia do Araripe e de $3 \mathrm{~km}$ para as demais bacias. Devido à escassez de recursos financeiros, grandes distâncias a serem percorridas e problemas operacionais, o alcance desta campanha ficou restrito a cobrir áreas das bacias sedimentares, onde a falta de dados gravimétricos comprometeria a modelagem gravimétrica tridimensional proposta neste trabalho.

As medidas plani-altimétricas foram adquiridas através de um sistema de posicionamento por satélite diferencial (DGPS) Magellan ProMax X. Utilizaramse estações de posicionamento (EP) do próprio IBGE como base para as medidas de posicionamento das estações gravimétricas. As EP do IBGE apresentam precisão milimétrica tanto na planimetria como na altimetria. Referências de nível do IBGE foram rastreadas diariamente com o objetivo de se verificar a precisão alcançada pelo posicionamento plani-altimétrico nas estações de medidas. O erro médio obtido foi de $15,28 \mathrm{~cm}$ na altimetria e inferior a $50 \mathrm{~cm}$ na planimetria. A precisão altimétrica de $\pm 0,15 \mathrm{~m}$ eqüivale a $\pm 0,04$ mgal. As correções gravimétricas usuais foram aplicadas a estes dados, sendo os mesmos também referenciados ao IGSN71 e integrados ao conjunto de estações gravimétricas já existentes.

A Fig. 2 apresenta a distribuição definitiva das 1.915 estações de medida consideradas para a confecção dos mapas gravimétricos das bacias rifte do Vale do Cariri. A cobertura gravimétrica atual não pode ser considerada como totalmente adequada para uma modelagem gravimétrica 3-D mais detalhada. Todavia, a disposição espacial dos pontos de observação, abrangendo quase que a totalidade das áreas de cobertura sedimentar, possibilita a aplicação do procedimento de interpretação computacional para a área da Bacia do Araripe, tendo porém um caráter preliminar para algumas áreas de menor cobertura. A Bacia do Rio do Peixe apresenta uma distribuição de estações gravimétricas bastante razoável, enquanto que a Bacia de Iguatu tem uma cobertura gravimétrica bem próxima da ideal. Visto que, estudos geofísicos regionais envolvendo a modelagem tridimensional deste conjunto de bacias sedimentares interiores são escassos até o momento, este trabalho vem a contribuir no

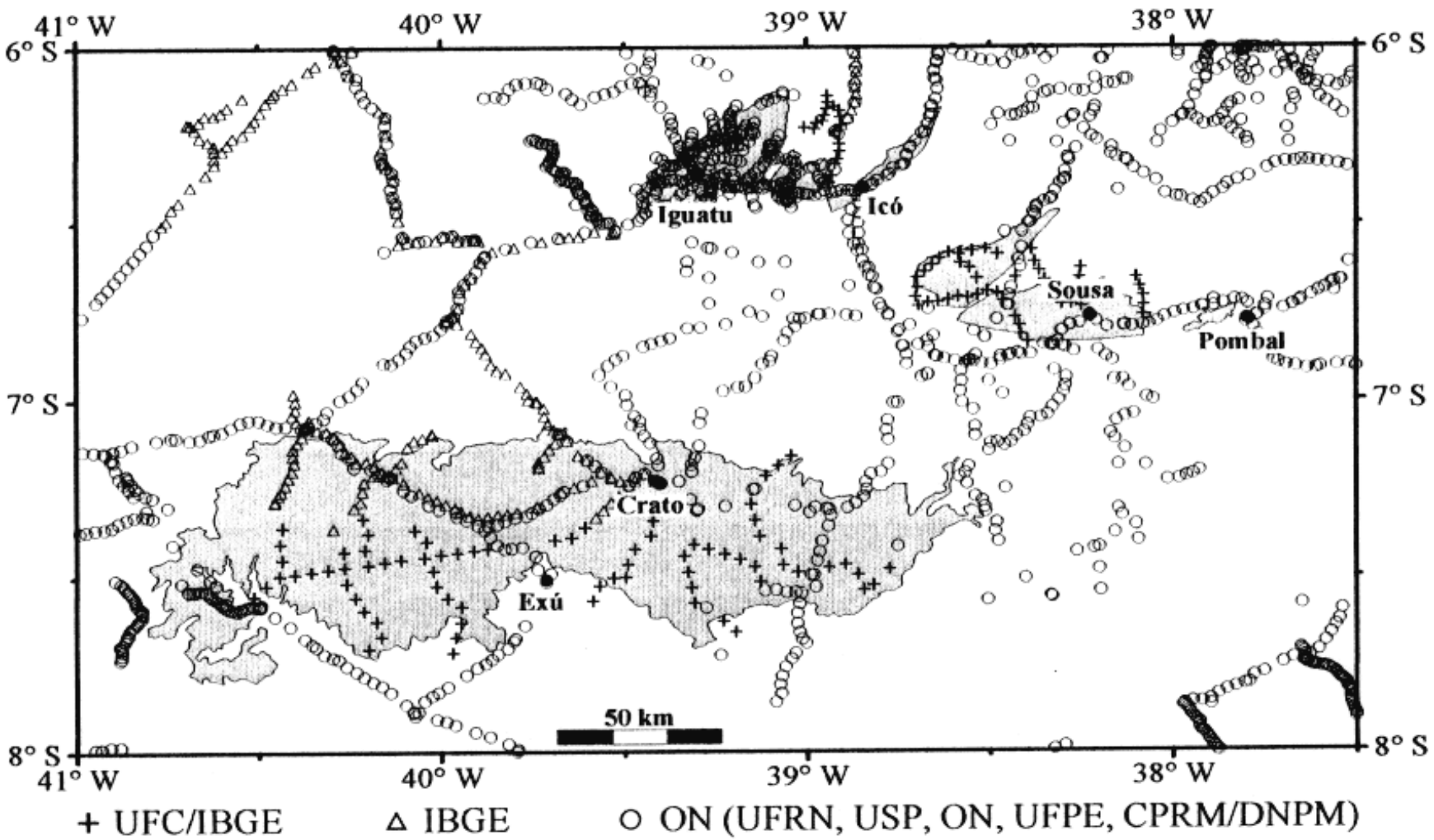

Figura 2- Mapa de localização das estações gravimétricas.

Figure 2- Location of gravity stations in the studied area. 
entendimento da geometria interna destas bacias em resposta aos esforços tectônicos mesozóicos ocorridos na Província Borborema.

Os dados selecionados foram interpolados em uma malha regular com espaçamento de $3 \mathrm{~km}$ nas direções $\mathrm{N}-\mathrm{S}$ e E-W. O mapa de anomalias Bouguer resultante (Fig. 3) é caracterizado pela presença de expressivos mínimos gravimétricos nas áreas onde as bacias rifte são identificadas em superfície. As anomalias negativas associadas à Bacia do Araripe (A na Fig. 3) apresentam forte orientação E-W, limitadas a norte pelas zonas de cisalhamento do Lineamento Patos. Mínimos localizados no âmbito da bacia indicam os principais depocentros das sub-bacias de Feitoria e Cariri. De modo similar, as anomalias na região da Bacia do Rio do Peixe também apresentam-se alongadas segundo a direção E-W do Lineamento Patos, ao longo do qual surge uma seqüência de mínimos locais, sugerindo áreas onde o pacote sedimentar é mais espesso (B na Fig. 3). As anomalias negativas relacionadas com as bacias de Iguatu, Malhada Vermelha e Lima Campos mostram uma orientação NE-SW, concordante com as falhas de Limoeiro e Orós (C na Fig.
3). Os gradientes gravimétricos mais expressivos ocorrem nas porções SE destas bacias, corroborando com a hipótese de uma série de bacias meio-graben com mergulho principal para NW. Na região das bacias Malhada Vermelha e Icó (ver Fig. 4c) não são observadas anomalias negativas. Certamente, tal fato se deva a pouca espessura sedimentar de tais bacias associada a prováveis variações laterais de densidade no interior do substrato cristalino.

Alguns outros mínimos relativos estão diretamente relacionados à ocorrência de corpos granitóides brasilianos do tipo Pereiro e metassedimentos diversos do Grupo Ceará (D e E na Fig. 3, respectivamente). Observa-se, ainda, um suave gradiente gravimétrico regional de aproximadamente $0,11 \mathrm{mgal} / \mathrm{km} \mathrm{com}$ orientação SSW-NNE, que evidencia uma tendência ascendente do campo gravimétrico em direção à linha de costa (de $-50 \mathrm{mgal}$ no extremo $\mathrm{SW}$ da área pesquisada a $-5 \mathrm{mgal}$ no limite NE). Tal efeito tem sua causa principal ligada ao afinamento crustal generalizado em direção à margem continental (Castro et al., 1998).

O componente regional devido às variações no

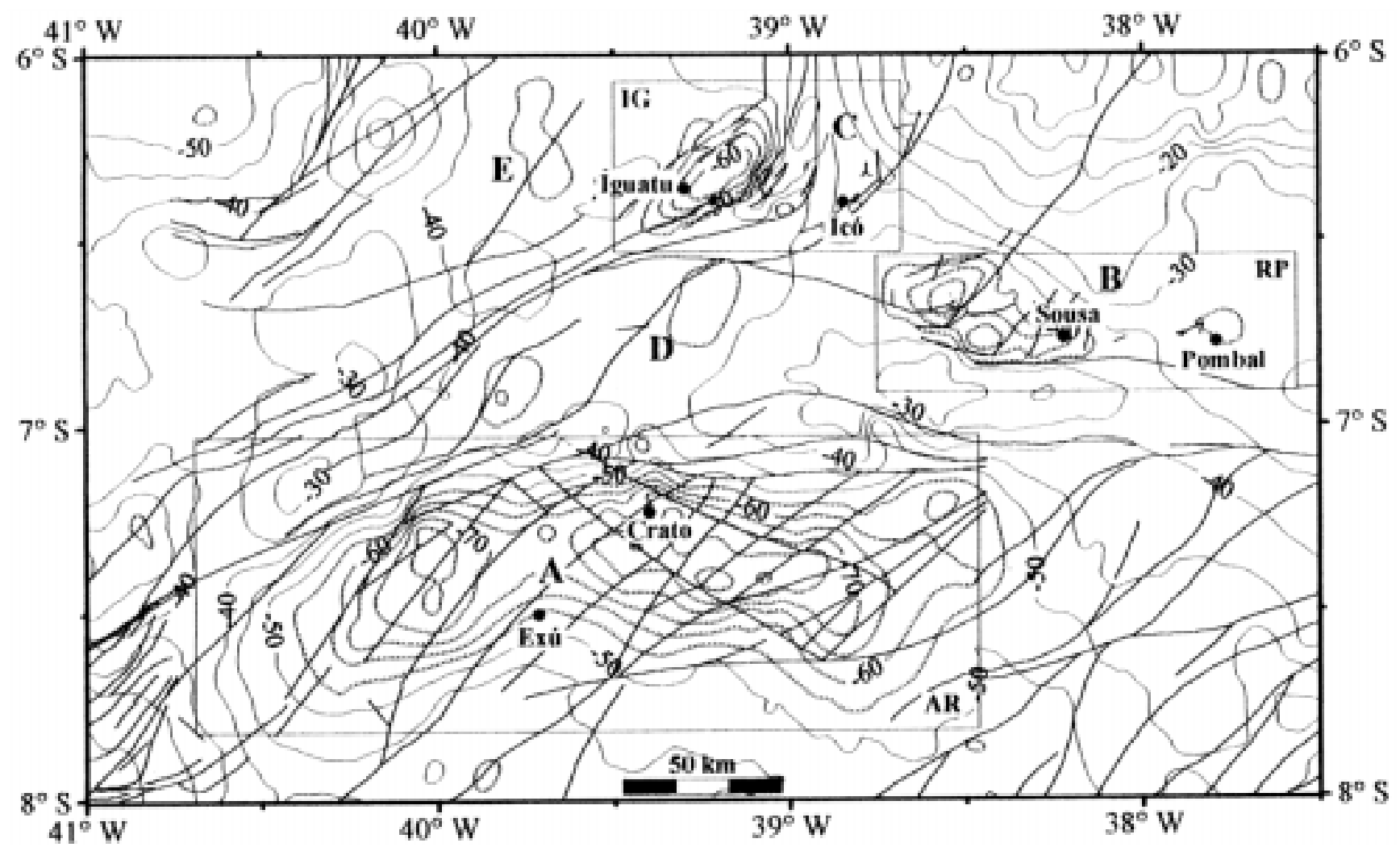

Figura 3- Mapa de anomalias Bouguer das bacias rifte do Vale do Cariri (AR - Araripe; IG - Iguatu, Malhada Vermelha e Icó; e RP - Rio do Peixe), mostrando as principais zonas de cisalhamento proterozóicas. Intervalo de contorno de 5 mgal.

Figure 3- Bouguer gravity anomaly map of the Cariri Valley rift basins (AR - Araripe; IG - Iguatu, Malhada Vermelha and Icó; and RP - Rio do Peixe), showing the main Proterozoic shear zones. Contour interval: 5 mgal. 
relevo da interface crosta-manto supracitadas foi extraído do campo gravimétrico total do Vale do Cariri através do método de ajuste polinomial robusto desenvolvido por Beltrão et al. (1991). Para um grau do polinômio pré-determinado, o procedimento iterativo modela os trends gravimétricos regionais a partir de uma superfície polinomial. A utilização de critérios estatísticos robustos torna o método de ajuste mais estável para polinômios de ordem superiores, eliminando o surgimento de pseudo-anomalias comuns a méto- dos de ajuste polinomial, que trabalham com o critério estatístico dos mínimos quadrados. O polinômio de grau 2 foi escolhido para promover a separação regionalresidual das anomalias Bouguer da área pesquisada. A Fig. 4 apresenta as anomalias gravimétricas residuais das bacias rifte do Vale do Cariri. O efeito regional foi satisfatoriamente removido, imprimindo um caráter ainda mais localizado às anomalias negativas associadas às coberturas sedimentares mesozóicas.

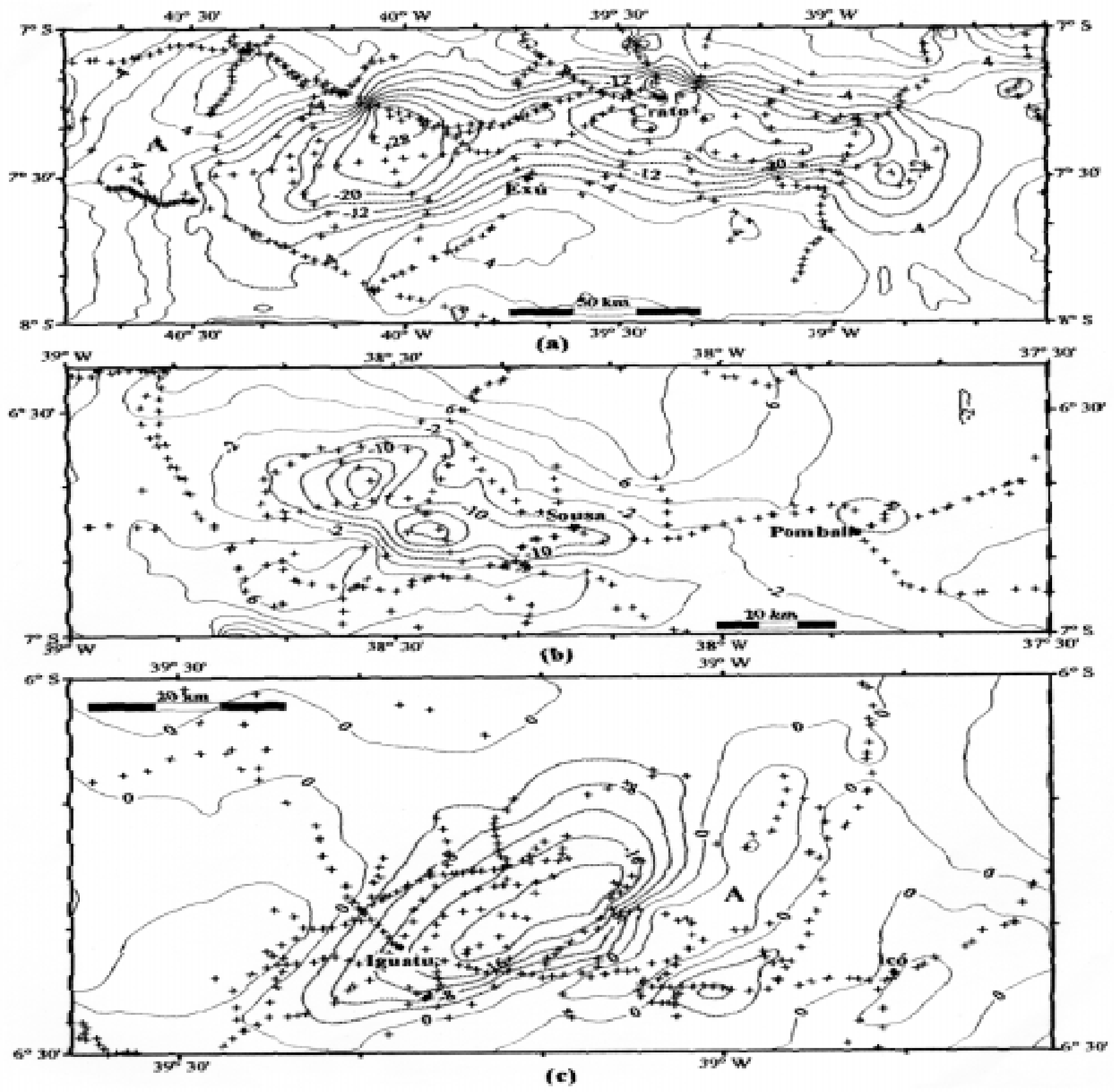

Figura 4- Mapas de anomalias gravimétricas residuais das bacias do Araripe (a), do Rio do Peixe (b) e da seqüência de bacias Iguatu, Malhada Vermelha, Lima Campos e Icó (c). Intervalo de contorno: 4 mgal.

Figure 4- Residual gravity anomaly maps of the rift basins: Araripe (a), Rio do Peixe (b), and the series of basins: Iguatu, Malhada Vermelha, Lima Campos and Icó (c). Contour interval: 4 mgal. 


\section{MODELAGEM GRAVIMÉTRICA 3-D}

O problema inverso aplicado em modelagem gravimétrica pode ser realizado através de dois procedimentos básicos. O primeiro fixa a geometria do modelo, normalmente formado por conjuntos de retângulos idênticos ou blocos quadrados, admitindo variações de densidades entre os blocos (Braile et al., 1974; Last \& Kubik, 1983; Barbosa \& Silva, 1993). O segundo procedimento envolve a modelagem das anomalias gravimétricas por meio de um ou mais corpos com densidade constante e geometria variável (Talwani \& Ewing, 1960; Al-Chalabi, 1972). Neste sentido, um conjunto de prismas verticais justapostos pode modelar o relevo de uma interface que separe dois meios homogêneos com contraste de densidade regular. A topografia do embasamento de uma bacia sedimentar é uma das situações geológicas clássicas que pode ser estimada por meio deste tipo de modelo geofísico.

Seguindo a abordagem de corpos com densidade
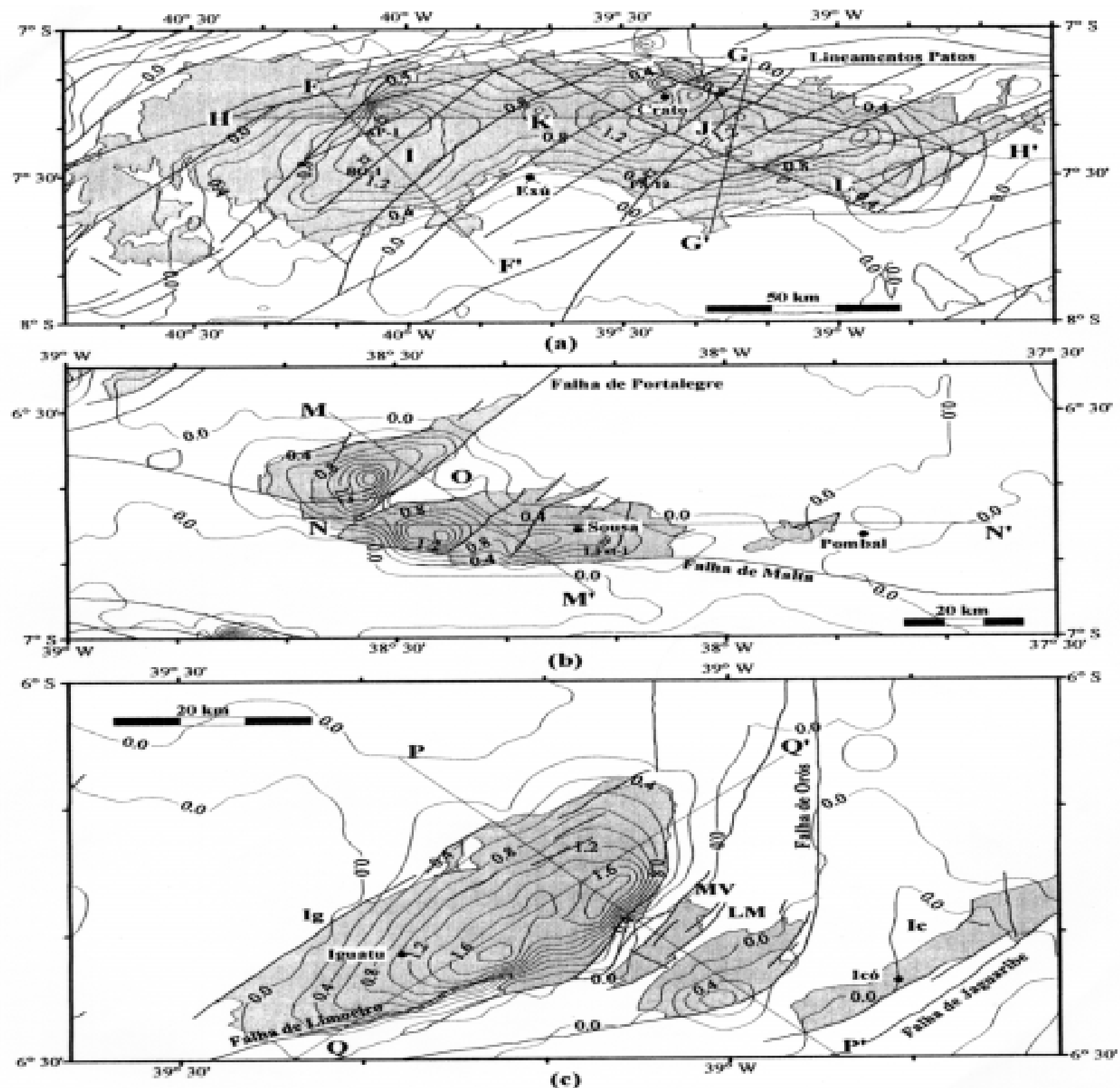

Figure 5-Modelos gravimétricos 3-D das bacias do Vale do Cariri: Bacia do Araripe (a), do Rio do Peixe (b) e bacias de Iguatu (Ig), Malhada Vermelha (MV), Lima Campos(LC) e Icó (Ic) (c). Intervalo de contorno: 0,2 km.

Figure 5-Three-dimensional gravity model of the Cariri Valley rift basins : Araripe (a), Rio do Peixe (b), and the series of basins: Iguatu (Ig), Malhada Vermelha (MV), Lima Campos(LC), and Icó (Ic) (c). Contour interval: $0.2 \mathrm{~km}$. 
constante e geometria variável, Rao \& Babu (1991) apresentaram um procedimento computacional para o modelagem geofísica de anomalias gravimétricas devidas a fontes tridimensionais com contraste de densidade lateralmente uniforme e linearmente decrescente com a profundidade. $\mathrm{O}$ modelo proposto pelos referidos autores considera que a diminuição no contraste de densidade $(\Delta \rho)$ em bacias sedimentares representa, do ponto de vista geológico, um aumento na compactação dos sedimentos em função da profundidade, que por sua vez pode ser aproximado pela seguinte função quadrática (Rao, 1986),

$$
\Delta \rho(z)=a_{0}+a_{1} z+a_{2} z^{2}
$$

onde $z$ representa a profundidade medida (positiva para baixo), $a_{0}$ é o valor do contraste de densidade na superfície e $a_{1}$ e $a_{2}$ são constantes da função quadrática.

As profundidades do relevo do embasamento são estimadas a partir das espessuras de prismas verticais justapostos, centrados sobre a malha regular obtida pela interpolação das observações gravimétricas. $\mathrm{O}$ valor inicial para a profundidade da base do prisma em um ponto $(i, j)$ qualquer da malha é obtido por

$$
Z(i, j)^{(1)}=g_{o b s}(i, j) / 2 \pi \gamma a_{0},
$$

onde $g_{o b s}$ é a anomalia gravimétrica observada e $\gamma$ é a constante gravitacional universal. O efeito gravimétrico devido ao conjunto total de prismas $\left(g_{\text {calc }}\right)$ é calculado para cada ponto da malha, usando-se as espessuras obtidas nas iterações prévias. A diferença entre as anomalias observada e estimada na $k$-ésima iteração $\left(\Delta g^{(k)}\right)$ é calculada e então uma nova estimativa para as espessuras dos prismas é obtida pela expressão

$$
Z(i, j)^{(k+1)}=\left[\Delta g(i, j)^{(k)} / 2 \pi \gamma \Delta \rho\right]+Z(i, j)^{(k)} .
$$

O processo é repetido até a anomalia estimada ajustar-se satisfatoriamente à anomalia observada. $\mathrm{O}$ modelo prismático final representa a melhor estimativa para o topo do embasamento cristalino da bacia sedimentar fornecida pelo método de inversão. Nas áreas onde a anomalia gravimétrica observada é positiva o algoritmo assume uma espessura igual a zero para o prisma.

O contraste de densidade é o único parâmetro a ser definido para inicializar o processo de inversão (Eqs. (2) e (3)). Como observado acima, existe uma relação inversa entre este parâmetro e as espessuras dos pris- mas verticais, enquanto que a geometria interna do modelo é determinada pelo comportamento da anomalia gravimétrica. Para analisar a ambigüidade existente entre o parâmetro contraste de densidade e as profundidades resultantes da modelagem, foram atribuídos vários valores para o contraste de densidade para cada uma das bacias sedimentares em particular. A escolha definitiva dos contrastes de densidade foi então determinada pela comparação dos resultados da modelagem e as informações obtidas através de interpretações gravimétricas independentes (Bedregal et al., 1992; Rand, 1984; Rand \& Manso, 1984), mapas sísmicoestruturais (Matos, 1992; Ponte \& Ponte Filho, 1996) e furos de sondagem (Brasil. MME- DNPM, 1979; Ghignone et al., 1986; Ponte et al., 1991). Devido a ausência de maiores conhecimentos sobre o comportamento do contraste de densidade com a profundidade nos pacotes sedimentares optou-se por trabalhar com o $\Delta \rho$ constante. Os valores de $a_{1}$ e $a_{2}$ foram então considerados iguais a zero. Os mapas estruturais do topo do embasamento das bacias rifte resultantes da aplicação do método de Rao \& Babu (1991) são apresentados na Fig. 5.

\section{Bacia do Araripe}

Para a Bacia do Araripe, as anomalias gravimétricas residuais atingem até -35 mgal nas áreas mais espessas (Fig. 4a). Valores anômalos desta ordem de grandeza são indicadores de um forte contraste de densidade entre os dois meios considerados (bacia sedimentar / embasamento) e/ou de espessuras consideráveis para o pacote sedimentar. Porém, a presença dos poços estratigráficos 2-AP-1-CE (Araripe), PS-12-CE (Projeto Santana) e 4-BO-1-PE (Bodocó) (Ponte \& Ponte Filho, 1996) permitiu a vinculação do processo de inversão, reduzindo a ambigüidade gerada por este par de parâmetros.

A espessura da coluna sedimentar no local do poço 2-AP-1-CE é da ordem de 1.480 m (Ponte et al., 1991). A utilização do contraste de $-0,50 \mathrm{~g} / \mathrm{cm}^{3}$ forneceu um modelo gravimétrico com profundidades da ordem de $1.500 \mathrm{~m}$ próximo ao referido poço profundo (Fig. 5a), ou seja, bastante condizente com a observação direta obtida na sondagem. O embasamento cristalino é alcançado a uma profundidade de $330,6 \mathrm{~m}$ no poço PS12-CE, $240 \mathrm{~m}$ acima das profundidades oferecidas pela inversão dos dados gravimétricos. Variações laterais na densidade média do pacote sedimentar podem ter provocado esta diferença considerável, visto que a seqüência sin-rifte está completamente ausente no poço. Por fim, no poço 4-BO-1-PE tem-se uma diferença de 
$420 \mathrm{~m}$, porém a análise do mapa de anomalias residuais (Fig. 4a) e do mapa Bouguer apresentado por Ponte \& Ponte Filho (1996) não mostra uma variação no campo gravimétrico capaz de indicar uma subida abrupta do topo do embasamento da ordem de $400 \mathrm{~m}$. Ponte \& Ponte Filho (1996) chamam a atenção para uma discrepância de $242 \mathrm{~m}$ entre a profundidade prevista para o embasamento pelo processamento sísmico e aquela constatada pela perfuração. Provavelmente, os registros da ficha técnica do poço deveriam ser revistos em trabalhos adicionais.

O mapa de profundidades do topo do embasamento da Bacia do Araripe (Fig. 5a) mostra

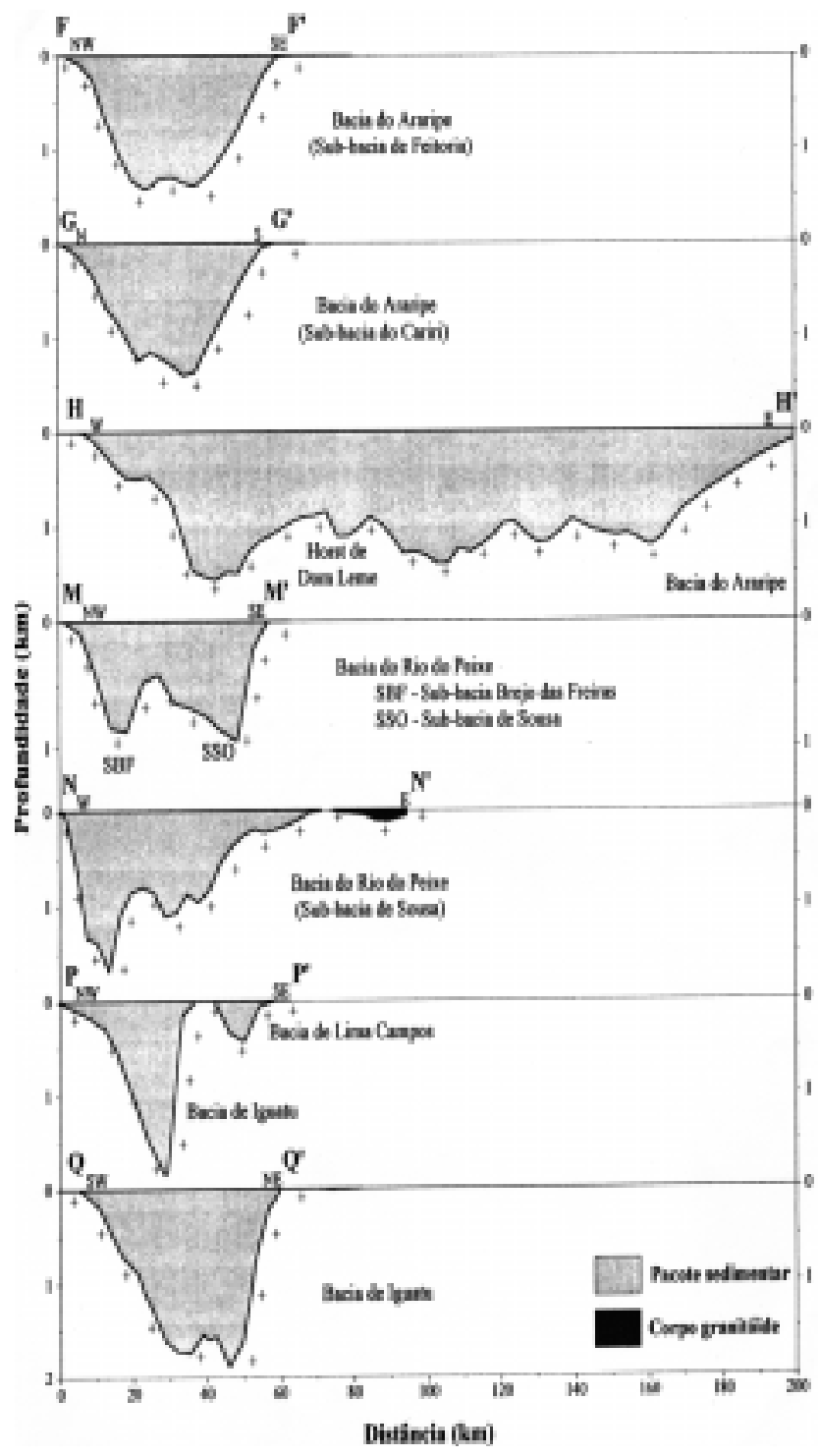

Figura 6-Seções transversais esquemáticas das bacias rifte do Vale do Cariri, obtidas a partir da modelagem gravimétrica 3-D. Suas localizações estão dispostas na Fig. 5.

Figure 6-Schematic cross-sections of the Cariri Valley rift basins from the three-dimensional model. Locations of sections are given in Fig. 5. uma boa concordância entre a área de abrangência da bacia, definida pela modelagem gravimétrica, e os seus contatos superficiais com o embasamento, observados pelos mapeamentos geológicos de superfície. Os limites norte e sul da bacia são especialmente bem marcados no mapa de profundidades. Por outro lado, no extremo leste a cobertura gravimétrica incipiente não permite uma melhor definição para os contornos subsuperficiais da bacia.

Com uma orientação preferencial para E-W, a arquitetura interna da Bacia do Araripe (Fig. 5a) apresenta um suave basculamento para SW na sua porção oeste. Nesta região, a bacia estende-se em profundidade até o extremo sul da área, além dos seus limites mapeados em superfície. O modelamento geofísico pôde ter incorporado o efeito gravimétrico negativo devido as rochas relativamente menos densas do embasamento da bacia, como por exemplo os granitóides do Sistema Piancó-Alta Brígida (Brito Neves, 1990) e/ou os sedimentos da Bacia de Socorro / Santo Ignácio (Assine, 1992), provocando um aumento indevido na espessura do pacote sedimentar.

No extremo oeste da bacia ( $\mathrm{H}$ na Fig. 5a), uma faixa do pacote sedimentar não pôde ser detectado pela modelagem gravimétrica. Nesta região, a cobertura sedimentar é bastante reduzida, com espessuras inferiores a $200 \mathrm{~m}$ (Assine, 1992), representadas pelos estratos tabulares e sub-horizontais da sequiência pós-rifte, o Grupo Araripe (Ponte \& Ponte Filho, 1996). Altos gravimétricos, presentes nesta região (A na Fig. 4a), mascaram o efeito negativo, relativamente mais incipiente, da fina sequiência sedimentar. Com base em dados gravimétricos e magnetométricos, Rand \& Manso (1984) interpretam tais anomalias positivas como sendo devidas a rochas básicas do substrato cristalino.

A configuração estrutural da Bacia do Araripe sugere tratar-se de uma bacia rifte, na sua porção inferior, formada por um conjunto de grabens assimétricos, colaterais e orientados segundo a direção NE-SW. Falhas normais condicionam a geometria interna da bacia, sendo os seus flancos norte e noroeste controlados por extensos falhamentos associados ao Lineamento Patos, com mergulhos acentuados para SSE (Perfis F-F' e G-G' - Fig. 6). Nestas regiões, o pacote sedimentar atinge rapidamente espessuras superiores a $1.500 \mathrm{~m}$ em áreas de maior espessura, que decrescem mais lentamente em direção aos limites sul da bacia. Sistemas de falhas com orientações NE-SW também condicionam parcialmente as bordas sul e sudeste, com mergulhos mais suaves (F', G' e H' na Fig. 5a e perfis F-F', G-G' e H-H' - Fig. 6).

Rand \& Manso (1984) calcularam profundidades 
superiores a $2.000 \mathrm{~m}$ na porção leste e $2.400 \mathrm{~m}$ na porção oeste da bacia. Estes autores partiram de um gradiente vertical de $66 \mathrm{~m} / \mathrm{mgal}$ obtido no poço exploratório LFst-1-PB, perfurado na Bacia do Rio do Peixe. Porém, tais espessuras sedimentares mostramse superestimadas, considerando as informações dos poços profundos, das seções sísmicas interpretadas por Ponte \& Ponte Filho (1996) e pelos resultados da modelagem gravimétrica 3-D em apreço. O contraste de densidade determinado para a modelagem da Bacia do Araripe $\left(-0,5 \mathrm{~g} / \mathrm{cm}^{3}\right)$ mostrou-se superior, em termos absolutos, aos contrastes das demais bacias rifte do Vale do Cariri $\left(-0,35 \mathrm{~g} / \mathrm{cm}^{3}\right)$. O uso de um contraste de $-0,35 \mathrm{~g} / \mathrm{cm}^{3}$ ocasionaria o aumento das profundidades finais semelhantes aos valores obtidos por Rand \& Manso (1984). A escolha de $-0,35 \mathrm{~g} / \mathrm{cm}^{3}$ para as bacias do Rio do Peixe e Iguatu será discutido adiante.

Dois depocentros principais podem ser identificados no eixo E-W da bacia (I e J na Fig. 5a), onde profundidades de até $1.600 \mathrm{~m}$ são observadas para o topo do embasamento. O Horst de Dom Leme (K na Fig. 5a) separa os dois depocentros nas sub-bacias de Feitoria, a oeste, e Cariri, a leste (Perfil H-H' - Fig. 6). A Sub-bacia de Feitoria (I na Fig. 5a) apresenta-se na forma de extenso graben limitado por falhas normais orientadas para NE-SW (Perfil F-F' - Fig. 6). Próximo ao poço 2-AP-1-CE a Sub-bacia de Feitoria atinge as suas maiores profundidades $(\sim 1.600 \mathrm{~m})$. Por sua vez, a Sub-bacia do Cariri (J na Fig. 5a) encontra-se orientada na direção E-W, sendo formada por dois grabens principais separados pelo Horst de Barbalha (perfis G-G' e H-H' - Fig. 6). Um depocentro secundário pode ser observado no extremo SW desta sub-bacia com espessuras em torno de $1.000 \mathrm{~m}$ (L na Fig. 5a). Ponte \& Ponte Filho (1996) denominam este depocentro de Graben do Serrote das Cacimbas-Palestina (Perfil HH' - Fig. 6).

No mapa sísmico-estrutural apresentado por Matos (1992) os referidos depocentros também podem ser observados, porém apresentam profundidades ligeiramente inferiores às da modelagem gravimétrica. A concordância entre o mapa sísmico-estrutural supracitado e o mapa de profundidades da Fig. 5a demonstra a capacidade do método de Rao \& Babu (1991) em obter uma boa estimativa para a geometria interna da bacia. Por fim, a concordância entre a estruturação tectono-sedimentar da Bacia do Araripe, demonstrada pela modelagem gravimétrica, e as zonas de cisalhamento proterozóicas do Lineamento Patos e da Zona Transversal (Fig. 5a), reforça a hipótese de reativações das zonas de fraqueza mais antigas durante os esforços tectônicos distensionais NW-SE das fa- ses sin-rifte I e II (Jurássico Superior ao Cretáceo Inferior). Todavia, como já analisado por Rand \& Manso (1984), vale ressaltar que a presença de variações de densidade consideráveis, entre os diferentes litotipos que compõem o embasamento cristalino da bacia deve provocar interferências locais nas estimativas de profundidade obtidas pela modelagem gravimétrica, como observado no limite sudoeste da Bacia do Araripe. Nestes casos, a premissa de meios homogêneos com contraste de densidade constante, suposta pelo método de inversão, estará sendo violada, reportando o procedimento interpretativo aos limites confiáveis que o método pode fornecer. A obtenção de um mapa estrutural do embasamento, mais acurado, demanda um nível de controle mais detalhado dos aspectos geológicos, o que já não corresponde aos objetivos do atual trabalho.

\section{Bacia do Rio do Peixe}

A escolha do contraste de densidade utilizada no procedimento de inversão dos dados gravimétricos no caso da Bacia do Rio do Peixe foi guiada pelo resultado do poço estratigráfico LFst-1-PB, localizado cerca de 10 km SE de Sousa (Fig. 5b). O embasamento cristalino foi alcançado a 989,90 $\mathrm{m}$ de profundidade (Brasil. MME-DNPM, 1979). Com um contraste de densidade igual a $-0,35 \mathrm{~g} / \mathrm{cm}^{3}$, a modelagem $3-\mathrm{D}$ forneceu valores para o topo do embasamento próximos a 900 m. Em termos absolutos, o contraste -0,35 $\mathrm{g} / \mathrm{cm}^{3}$ é inferior ao valor definido para a Bacia do Araripe $\left(-0,5 \mathrm{~g} / \mathrm{cm}^{3}\right)$. A seqüência pós-rifte, presente apenas na Bacia do Araripe, pode estar provocando uma diminuição no valor da densidade média dos sedimentos desta bacia.

A geometria interna da Bacia do Rio do Peixe é fortemente condicionada pelas zonas de cisalhamento Malta (parte do Lineamento Patos) e Portalegre (Fig. 5b), que secionam a bacia em três blocos distintos: as sub-bacias Brejo das Freiras, Sousa e Pombal. As anomalias gravimétricas residuais relacionadas às coberturas sedimentares são da ordem de -18 mgal (Fig. 4b), sugerindo que as sub-bacias Brejo das Freiras e Sousa tenham espessuras semelhantes. A Sub-bacia de Pombal por não apresentar cobertura gravimétrica adequada não será analisada neste trabalho.

A compartimentação estrutural da Sub-bacia Brejo das Freiras encontra-se associada à zona de inflexão da Falha de Portalegre (Fig. 5b). A borda SE da sub-bacia apresenta mergulho forte para NW, com o topo do embasamento atingindo profundidades de até 1.900 m na porção central do graben (Perfil M-M' - 
Fig. 6). Os limites W e NW da sub-bacia, obtidos pela modelagem gravimétrica, estendem-se alguns quilômetros além dos contatos superficiais da cobertura sedimentar. O efeito gravimétrico negativo associado a um corpo granítico, aflorante no extremo oeste da área (ver mapa geológico 1:250.000 do Projeto Rio Jaguaribe, Brasil. MME-DNPM, 1979), somado à ausência de observações gravimétricas, além dos limites NW da cobertura sedimentar (Fig. 2), faz com que o procedimento de inversão não apresente uma estimativa mais acurada para a geometria interna da subbacia Brejo das Freiras neste local.

A Sub-bacia de Sousa tem seu eixo principal orientado segundo a direção E-W da Falha de Malta (Fig. 5 b e Perfil N-N' - Fig. 6). Dois depocentros podem ser observados na porção sul da sub-bacia, com profundidades em torno de $1.700 \mathrm{~m}$, a oeste, e $1.100 \mathrm{~m}$, próximo a cidade de Sousa, separados por um alto do embasamento, cujo topo encontra-se a $700 \mathrm{~m} \mathrm{de}$ profundidade (Perfil N-N' - Fig. 6). Em direção ao flanco norte, as espessuras dos sedimentos diminuem, gradativamente, até os limites superficiais da sub-bacia. O batólito granítico da Serra Mata do Coco, aflorante a leste da Falha de Portalegre entre as duas sub-bacias (não apresentado na Fig. 5b), provoca uma distorção no mapa de profundidades, acusando a presença dos sedimentos mesozóicos nesta área de rochas cristalinas (O na Fig. 5b). Portanto, as espessuras do pacote sedimentar no flanco NW da Sub-bacia Sousa devem estar superestimadas devido à contribuição do efeito negativo do corpo ígneo ao campo gravimétrico local.

Rand (1984) obteve estimativas para as espessuras da Bacia Rio do Peixe através da relação de $66 \mathrm{~m} /$ mgal entre a anomalia gravimétrica e a profundidade do topo do embasamento no poço estratigráfico LFst1-PB. Tais valores são inferiores em até $400 \mathrm{~m}$ em relação as profundidades obtidas pelo método de Rao \& Babu (1991). Rand (1984) considera suas estimativas seguras pelo fato do poço ser afastado da borda da bacia e a anomalia Bouguer ter comportamento planar no local do poço. Contudo, a modelagem gravimétrica em apreço indica que o poço ainda encontra-se na região de borda da bacia, o que evidencia que o fator de $66 \mathrm{~m} / \mathrm{mgal}$ foi relativamente subestimado. Françolin et al. (1994) apresentam duas seções esquemáticas da bacia do Rio do Peixe, nas quais o comportamento estrutural do topo do embasamento é concordante com os resultados da modelagem gravimétrica realizada. Estes autores basearam-se, principalmente, em dados geológicos de superfície e nos resultados dos levantamento gravimétrico de Rand (1984).

Um mínimo gravimétrico da ordem de -4 mgal aparece a norte da cidade de Pombal (Fig. 4b), indicando a presença de um corpo com contraste de densidade negativo, possivelmente uma rocha de composição granítica, aflorante nas proximidades da cidade de Pombal. A inversão das anomalias residuais fornece profundidades de até $400 \mathrm{~m}$ para a base deste corpo granitóide. Porém, considerando-se que as rochas graníticas têm densidades médias superiores às densidades dos sedimentos, as profundidades obtidas para o corpo intrusivo devem estar superestimadas.

\section{Bacias de Iguatu, Malhada Vermelha, Lima Campos e Icó}

Após vários testes, o contraste de densidade utilizado na modelagem da Bacia de Iguatu foi estabelecido em $-0,35 \mathrm{~g} / \mathrm{cm}^{3}$. Para a escolha deste parâmetro, levouse em consideração os resultados da modelagem gravimétrica de Bedregal et al. (1992) e o valor estabelecido para a Bacia do Rio do Peixe.

Tais bacias interiores representam um agrupamento de bacias rasas com geometria interna do tipo meio-graben assimétrico, localizadas nos blocos a NW de falhas normais com direção NE-SW e com mergulho para W-NW, reativando as zonas de cisalhamento proterozóicas (Limoeiro, Orós e Jaguaribe). As respectivas anomalias gravimétricas residuais e o modelo geofísico 3-D estão ilustrados nas Figs. 4c e 5c.

A Bacia de Iguatu possui a seção sedimentar mais expressiva desta região, que chega a alcançar espessuras superiores a $1.800 \mathrm{~m}$ (Fig. 5c). Utilizando diferentes técnicas de interpretação gravimétrica, Bedregal et al. (1992) obtiveram valores um pouco inferiores para as profundidades do topo do embasamento, atingindo cerca de $1.700 \mathrm{~m}$ no depocentro da bacia. As estações gravimétricas levantadas pela UFC/IBGE (Fig. 2) permitiram uma melhor definição dos limites NW da bacia em relação ao modelo apresentado por Bedregal et al. (1992).

A geometria interna da bacia é fortemente controlada pelas feições estruturais observadas em superfície. As falhas associadas as zonas de cisalhamento neoproterozóicas Limoeiro e Orós apresentam uma pronunciada inflexão (Fig. 5c), partindo de direções NE-SW, a sul da bacia, para N-S mais a norte. O falhamento mesozóico que reativou tais feições estruturais antigas condicionam uma forma alongada e em cunha à bacia, segundo o eixo NE-SW, com os seus flancos NW e SE apresentando mergulhos fortes (Perfil P-P' - Fig. 6). As maiores espessuras sedimentares concentram-se próximas da borda SE, 
onde localiza-se o depocentro da bacia, alongado segundo a direção da falha principal de borda (Perfil QQ' da Fig. 6).

A Bacia de Malhada Vermelha (MV na Fig. 5c) não apresenta anomalias residuais significativas para serem detectadas pelo método de inversão dos dados gravimétricos. O substrato desta bacia é formado pelos metassedimentos diversos (gnaisses e quartzitos) do Grupo Ceará (Brasil, DNPM, 1979), que geram uma anomalia gravimétrica positiva dentro da Faixa Orós (A na Fig. 4c). A contribuição desta unidade precambriana, relativamente mais densa que as rochas do Complexo Caicó adjacente, ao campo gravimétrico mascara o efeito gravitacional negativo devido a tal bacia sedimentar.

A Bacia de Lima Campos situa-se na região de inflexão da zona de cisalhamento de Orós e apresenta uma configuração estrutural bastante semelhante à Bacia de Iguatu (Figs. 1 e 5c). A modelagem gravimétrica forneceu profundidades de até $650 \mathrm{~m}$ para o topo do embasamento. A borda SE da bacia é caracterizada por um mergulho abrupto, concordante com a expressão em profundidade do sistema de falhas que reativaram a zona de cisalhamento de Orós (Perfil PP' - Fig. 6).

A Bacia de Icó apresenta uma cobertura sedimentar muito incipiente com espessuras inferiores a 200 m. A maior concentração de sedimentos ocorre na porção norte da bacia, localizada a NW da zona de cisalhamento Jaguaribe (Fig. 5c). A pouca cobertura gravimétrica não permite tecer maiores inferências sobre a arquitetura interna desta bacia.

\section{IMPLICAÇÕES TECTÔNICAS NA IMPLAN- TAÇÃO DẢS BACIAS RIFTE}

A principal fase do sistema de rifteamento do Nordeste do Brasil (fase sin-rifte II) ocorreu durante o Neocomiano - Barremiano, com o desenvolvimento dos principais rift - valleys associados a um extenso fraturamento da crosta superior (Matos, 1992). A deformação distensional com estiramento na orientação NW-SE originou um importante eixo de afinamento crustal NE-SW, com a subida da interface crosta-manto. Na região da crosta continental menos espessa estão localizadas as bacias intracratônicas do Vale do Cariri, além do graben principal da porção emersa da Bacia Potiguar (Castro \& Medeiros, 1997). Durante o estágio inicial, um lento processo de subsidência mecânica regional teria propiciado a deposição dos estratos sedimentares da seqüência pré-rifte da Bacia do Araripe (Ponte \& Ponte Filho, 1996). Com o início do processo de deformação rúptil, um severo fendilhamento tafrogênico deu origem à um sistema de riftes, que acompanharam as feições estruturais antigas. Este conjunto de bacias rifte orientadas segundo o eixo principal da deformação distensional foi denominado de Trend Cariri-Potiguar por Matos (1992).

A arquitetura interna das bacias do Vale do Cariri, definida pela modelagem gravimétrica, descreve um conjunto de grabens e meio-grabens assimétricos, pouco profundos (inferiores a $2.000 \mathrm{~m}$ ) e com mergulho forte principalmente para NW (Figs. 1, 5 e 6). Os modelos geofísicos delineiam o comportamento em profundidade das falhas normais e de transferência que condicionam o arcabouço geométrico das bacias. Essas feições estruturais mesozóicas acompanham as zonas de cisalhamento neoproterozóicas (Figs. 5 e 6). Tal fato evidencia a decisiva atuação da herança tectônica do embasamento na configuração final das bacias, com a reativação das zonas de fraqueza crustal preexistentes durante a deformação distensional neocomiana.

A Bacia do Araripe tem uma coluna litoestratigráfica completa, apresentando as tectonoseqüências pré, sin e pós-rifte. Seu arcabouço estrutural é formado por grabens assimétricos, orientados por falhas normais com orientação NE-SW. As bordas NNW e sul são fortemente controladas por falhamentos E-W e NW-SE, que reativaram as zonas de cisalhamento dos lineamentos Patos e Pernambuco como zonas de transferências (Figs. 5a e 6). O Horst de Dom Leme atinge profundidades de até $800 \mathrm{~m} \mathrm{(K}$ na Fig. 5a), separando a bacia rifte em duas sub-bacias com até $1.600 \mathrm{~m}$ de estratos sedimentares.

O rifteamento responsável pela seqüência sin-rifte da Bacia do Araripe também formou os meio-grabens assimétricos das bacias do Rio do Peixe e Iguatu. Contudo, tais bacias não apresentam as seqüências pré e pós-rifte da Bacia do Araripe, sendo precocemente abortadas ainda no estágio de estiramento crustal com basculamento de blocos (Ponte \& Ponte Filho, 1996). A arquitetura interna da Bacia do Rio do Peixe é dominada pelas reativações eocretácicas dos falhamentos precambrianos de Malta (E-W) e Portalegre (NE-SW), que dividem a bacia em duas sub-bacias principais. A Sub-bacia de Brejo das Feiras localiza-se no bloco rebaixado a NW da Falha de Portalegre, acumulando até $1.900 \mathrm{~m}$ de sedimentos. Enquanto que, a Sub-bacia de Sousa tem sua borda sul definida pela Falha de Malta, contendo até $1.700 \mathrm{~m}$ de espessura sedimentar distribuída em dois depocentros alinhados na direção E-W (Figs. 5b e 6). Já o conjunto de bacias de Iguatu, Malhada Vermelha, Lima Campos e Icó ocorre na região de inflexão das zonas de cisalhamento Limoeiro, 
Orós e Jaguaribe. Esta região é dominada por uma sequiência de meio-grabens, que concentra até 1.800 $\mathrm{m}$ de estratos sedimentares nos blocos rebaixados a NW das respectivas falhas precambrianas (Figs. $5 \mathrm{c} \mathrm{e}$ $6)$.

\section{CONCLUSÕES}

Um procedimento iterativo de interpretação gravimétrica foi aplicado ao mapa de anomalias Bouguer das bacias rifte do Vale do Cariri. As profundidades para o topo do embasamento obtidas por este método de inversão foram vinculadas indiretamente a informações oriundas de levantamentos geofísicos independentes e furos de sondagem realizados na região. Tal procedimento resultou em estimativas para a arquitetura interna das bacias consistentes com o conhecimento geológico e tectônico atual.

A modelagem gravimétrica 3-D permitiu delinear um arcabouço geométrico para essas bacias interiores bastante condizente com os modelos geodinâmicos para a evolução do rifteamento no Nordeste do Brasil, desenvolvidos por Chang et al. (1992), Matos (1992) e (Ponte \& Ponte Filho, 1996). O conjunto de bacias rifte, formadas por grabens e meio-grabens rasos e assimétricos, representa a conjugação dos esforços tectônicos distensionais eocretácicos da Trafogenia Vealdeniana, atuando sobre blocos gnaíssicos arqueanos e paleoproterozóicos e faixas supracrustais paleo e neoproterozóicas intensamente deformados durante a Orogênese Brasiliana. A reativação mesozóica destas zonas de fraqueza mais antigas está evidenciada claramente na arquitetura 3-D das bacias do Vale do Cariri.

\section{AGRADECIMENTOS}

Este trabalho só se tornou possível devido a concessão dos dados gravimétricos da região do Vale do Cariri pelo Instituto Brasileiro de Geografia e Estatística (IBGE) e Observatório Nacional / CNPq. Os autores agradecem às instituições que forneceram seus dados geofísicos ao Observatório Nacional. São elas: UFRN, USP, UFOP, UFPE e CPRM/DNPM. À Divisão de Geociências (DIGEO Fortaleza) do IBGE somos gratos pela parceria que permitiu a realização do levantamento gravimétrico complementar. Ao Dr. B. B. Brito Neves e aos revisores anônimos somos gratos pela leitura crítica e importantes sugestões ao texto, bem como aos bolsistas de Iniciação Científica (CNPq) do LGPSR - UFC que participaram dos trabalhos de campo e da digitalização dos mapas geológicos. Este trabalho teve o apoio financeiro do CNPq na forma de bolsa de Desenvolvimento Científico Regional para DLC.

\section{REFERENCIAS}

AL-CHALABI, M. - 1972 - Interpretation of gravity anomalies by non-linear optimisation. Geophys. Prosp., 20: $1-16$.

ALMEIDA, F.F.M. - 1967 - Origem e evolução da plataforma brasileira. Bol. Div. Geol. Mineral, Ministério de Minas e Energia, DNPM, Rio de Janeiro, 241 pp.
ARAI, M., COIMBRA, J.C. \& TELLES JR., A.C.S. - 1989 Estudo bioestratigráfico das bacias interiores Mesozóicas do Nordeste Brasileiro. Relatório de Progresso, Petrobrás - Cenpes - Sebipe, 46 pp.

ASSINE, M. L. - 1992 - Análise estratigráfica da bacia do Araripe, Nordeste do Brasil. Revista Brasileira de Geociências, 22(3): 289-300.

BARBOSA, V.C.F. \& SILVA, J.B.C. - 1993 - Reconstituição Gravimétrica Compacta. Anais do III Congresso Internacional da SBGf, Resumos Expandidos, 2: 765-767, Rio de Janeiro - RJ.

BEDREGAL, R.P., LINS, F.A.P.L., BOA HORA, M.P.P., MOREIRA, J.A.M. \& MACÊDO, J.W.P. - 1992 - Modelagem gravimétrica bi e tridimensional da bacia de Iguatu, Ceará. Anais do XXXVII Congresso Brasileiro de Geologia, Resumos Expandidos, 2: 383-384, Camburiú - SP.

BELTRÃO, J. F., SILVA, J.B.C. \& COSTA, J.C. - 1991 Robust polynomial fitting method for regional gravity estimation. Geophysics, 56: 80-89.

BRAILE, L.W., KELLER, G.R. \& PEEPLES, W.J. - 1974 Inversion of gravity data for two-dimensional density distributions. J. Geophys. Res., 79: 2017-2021.

BRASIL. MME - DNPM - 1979 - PROJETO RIO JAGUARIBE, Estados do Ceará, Rio Grande do Norte e Paraíba - Relatório Final de Geologia (Escala 1:25.000), Brasília, 149pp.

BRASIL. MME - DNPM - 1981 - PROJETO RADAMBRASIL, Levantamento de Recursos Naturais, V. 23 - Folhas SB. 24/25 Jaguaribe / Natal (Escala 1:1.000.000), Rio de Janeiro, 486pp.

BRITO NEVES, B.B. - 1990 - A bacia do Araripe no contexto geotectônico regional. Anais do I Simpósio sobre a Bacia do Araripe e bacias interiores do Brasil, Atas, 2133.

CAMPANHA, V.A. - 1987 - Análises bioestratigráficas do poço 2-AP-1-CE, IPT report. Relatório 24769, 33 pp.

CASTRO, D.L. \& MEDEIROS, W.E. - 1997 - Afinamento crustal associado à implantação das bacias intracratônicas do trend Cariri-Potiguar. XVII Simpósio de Geologia do Nordeste, Resumos Expandidos, 334338, São Paulo - SP.

CASTRO,D.L., MEDEIROS, W.E., JARDIM DESÁ,E.F.\& MOREIRA, J.A.M. - 1998 - Mapa gravimétrico do Nordeste Setentrional do Brasil e margem continental adjacente: interpretação com base na hipótese de isostasia. Revista Brasileira de Geofísica, 16 (2/3): 115-131.

CHANG,H.K., KOWSMANN, R.O., FIGUEIREDO, A.M.F. \& BENDER, A.A. - 1992 - Tectonics and stratigraphy of the East Brazil Rift system: an overview. Tectonophysics, 213: 97-138.

FRANÇOLIN, J.B.L., COBBOLD, P.R. \& SZATMARI, P. 1994 - Faulting in the Early Cretaceous Rio do Peixe basin (NE Brazil) and its significance for the opening of the Atlantic. Journal of Structural Geology, 16 (5): 647 661.

GHIGNONE, J. I., COUTO, E. A. \& ASSINE, M. L. - 1986 - 
Estratigrafia e Estrutura das Bacias do Araripe, Iguatu e Rio do Peixe. Anais do XXXIV Congresso Brasileiro de Geologia, 1: 271-285, Goiânia-GO.

JARDIM DE SÁ, E.F. - 1994 - A Faixa Seridó (Província Borborema, NE do Brasil) e o seu significado geodinâmico na Cadeia Brasiliana/Pan-Africana. Tese de Doutorado, UnB, Brasília - DF, 804 pp.

LAST, B.J. \& KUBIK, K. - 1983 - Compact gravity inversion. Geophysics, 48 (6): 713-721.

MATOS, R.M.D. - 1987 - Sistema de rifts Cretáceos do Nordeste Brasileiro. In: Anais, Tectos, Petrobrás - Depex, 126-159.

MATOS, R.M.D. - 1992 - The northeast brazilian rift system. Tectonics, 11 (4): 766-791.

OLIVEIRA, E. - 1983 - A Chapada do Araripe e sua representação pela gravimetria. Petrobrás/CENPES/SEMEPO, Relatório Interno, Rio de Janeiro.

PONTE, F.C., HASHIMOTO, A.T. \& DINO, R. - 1991 - Geologia das bacias mesozóicas do interior do Nordeste do Brasil. Petrobrás/CENPES/DIVEX/SEBIPE, Relatório Interno, Rio de Janeiro - RJ.

PONTE, F.C. \& PONTE FILHO, F.C. - 1996 - Estrutura geológica e evolução tectônica da Bacia do Araripe. DNPM, Recife - PE, 68 pp.
RAND, H.M. - 1984 - Reconhecimento gravimétrico da bacia do Rio do Peixe, Paraíba. Anais do XI Simpósio de Geologia do Nordeste, Atas, Boletim no 9: 42-47, Natal - RN.

RAND, H.M. \& MANSO,V.A.V. - 1984 - Levantamento gravimétrico e magnetométrico da bacia Araripe, XXXIII Congresso Brasileiro de Geologia, Anais, 4: 2011-2016, Rio de Janeiro - RJ.

RAO, D.B. - 1986 - Modelling of sedimentary basins from gravity anomalies with variable density contrast. Geophys. J. Royal Astr. Soc., 84 (1): 207-212.

RAO, D.B. \& BABU, N.R. - 1991 - A Fortran-77 computer program for three-dimensional analysis of gravity anomalies with variable density contrast. Computers and Geociences, 17 (5): 655-667.

SÁ, J.M., McREATH, I. \& LETERRIER, J. - 1995 - Petrology, geochemistry and geodynamic setting of proterozoic igneous suites of the Orós fold belt (Borborema Province, Northeast Brazil). J. South America Earth Sciences, 8: 299-314.

TALWANI, M. \& EWING, M. - 1960 - Rapid computation of gravitational attraction of three-dimensional bodies of arbitrary shape. Geophysics, 25 (1): 203-225.

Manuscript submitted December 15, 1998 Revised version accepted January 20, 2000

\section{CHARACTERIZATION OF THE INTERNAL ARCHITECTURE OF THE CARIRI VALLEY RIFT BASINS, BASED ON 3D GRAVITY MODELING}

A series of northeast trending shallow intracratonic basins - Araripe, Rio do Peixe, Iguatu, Malhada Vermelha, Lima Campos and Icó - are located in the Cariri Valley, central northeastern Brazil. These Early Cretaceous rift basins have been described as asymmetric half grabens separated by basement highs and transfer faults. Their dimensions do not exceed a few tens kilometers in width. The Precambrian basement is represented by several structural domains encompassed in the Borborema province (Fig. 1). The entire province was highly deformed and metamorphosed during the Late Proterozoic Brasiliano Cycle $( \pm 600 \mathrm{Ma})$. Brasiliano shear zones trending E-W and NE-SW were reactivated during the northeast Brazilian rift system associated with the breakup of the Gondwana supercontinent and the opening of the South Atlantic. The structural reactivation of these ancient upper crustal weakness zones controlled the internal geometry of the Cariri Valley basins. The intracratonic basins record in their geometrical framework the relationship between Cretaceous extensional deformation and the reactivation of Precambrian shear zones. In this context, gravity modeling is a helpful tool to improve estimates about the overall geometry of the rift basins and their tectonic evolution.

Most of the gravity observations in the Cariri Valley were made by the Instituto Brasileiro de Geografia e Estatística (IBGE) and Observatório Nacional (ON). These data sets were merged allowing for the production of a Bouguer gravity anomaly map of the sedimentary basins. The gravity coverage was further improved by additional campaigns carried out by the Laboratório de Geofísica de Prospecção e Sensoriamento Remoto (LGPSR/UFC) with operational support provided by IBGE. All gravity measurements were made with a LaCoste \& Romberg gravimeter, and a couple of Magellan ProMax X receptors allowed for the DGPS positioning of the gravity stations. All gravity values have been referred to the International Gravity Standardization Net 1971 - IGSN 71. Fig. 2 shows the distribution of the 1,915 gravity stations considered in this study. Gravity distribution is satisfactory for Rio do Peixe and Iguatu basins and, although not completely adequate for the other basins, this data set was used to build 3D gravity models, which might be considered preliminary in some areas of the Araripe basin.

The Bouguer anomaly map of all Cariri Valley basins is shown in Fig. 3. A regional gravity gradient was removed by a regional-residual separation method based on robust polynomial fitting (Beltrão et al., 1991). An iterative computer method for 3D analysis of gravity anomalies was applied to the residual anomaly maps of the intracratonic basins (Fig. 4). The modeling program was developed by Rao \& Babu (1991) and calculates the gravity anomalies of three-dimensional vertical prisms placed in juxtaposition at each point of the gridded data. The 
depths to the basement are adjusted iteratively by comparing the calculated anomalies with the observed data. Local geology observations and geophysical information gathered from boreholes, seismic sections and previous gravity interpretations were taken into account to constrain in an indirect manner the 3D modeling results. The basement topography maps of the rift basins so obtained by this method are shown in Fig. 5.

Examination of the basement contour maps shows a series of asymmetric grabens and half grabens trending NE-SW. The E-W trending Araripe basin is separated by two main subbasins: Feitoria (western graben) and Cariri (eastern graben). These subbasins have up to $1,600 \mathrm{~m}$ of sediments and are separated by the Dom Leme Horst (Fig. 5a). Reactivation of the Patos shear zone as normal and transfer faults constrained the northern and southern borders of the Araripe basin. The gravity model agrees with the seismostructural maps presented by Matos (1992) and Ponte \& Ponte Filho (1996).

The Rio do Peixe basin encompasses the Brejo das Feiras, Sousa and Pombal subbasins. This rift basin is bounded by Precambrian shear zones (Figs. 1 and 5b). The Brejo das Freiras subbasin is controlled by the NE-SW trending Portalegre fault and shows structural dip to NW. The sedimentary sequence is up to $1,900 \mathrm{~m}$ thick close to its SW border. On the other hand, the E-W trending Malta fault - a segment of the Patos shear zone - marks the southern boundary of the Sousa subbasin. Two depocenters can be observed in the E-W trending basin axis, filled with up to 1,700 m of sin-rift sediments (Fig. 5b and 6).

The Iguatu, Malhada Vermelha, Lima Campos and Icó basins encompass a sequence of shallow, asymmetric half graben basins, located in the NW flanks of the NE-SW trending shear zones (Figs. 5c and 6). The concave shapes of these rift basins are attributed to the E-W to N-S bending of the Late Proterozoic Orós and Jaguaribe shear zones. The Iguatu and Lima Campos are the main intracratonic basins in this region, being infilled by $1,800 \mathrm{~m}$ and $600 \mathrm{~m}$ of sediments, respectively.

The 3D gravity modeling produced estimates the internal geometry of the Cariri Valley rift basins. The architecture of these basins is well constrained by a NE-SW and E$\mathrm{W}$ trending system of intracontinental normal and transfer faults. These Mesozoic structural features are concordant with Late Proterozoic shear zones (Figs. 1, 5 and 6). This fact demonstrates the decisive contribution of the basement tectonic heritage to the basinal final framework, with reactivation of preexisting upper crustal weakness zones during the Early Cretaceous extensional deformation in northeastern Brazil.

\section{NOTA SOBRE OS AUTORES}

\section{David Lopes de Castro}

David L. Castro é Geólogo (UFRN, 1986), Mestre em Geofísica (UFPA, 1990) e Doutor em Geofísica (Univ. Kiel Alemanha, 1995). Entre 1996 e o início de 1998, ele esteve associado ao Departamento de Física e ao Programa de Pesquisa e Pós-graduação em Geodinâmica e Geofísica da UFRN, com bolsa de Recém-Doutor do CNPq. Neste período, orientou uma dissertação de mestrado. Entre 1998 e 1999, participou do Projeto Nordeste - Reconhecimento Geofísico e Hidrogeológico da região costeira entre Fortaleza e Paracuru, Norte do Ceará, junto ao Laboratório de Geofísica de Prospecção e Sensoriamento Remoto (LGPSR) da UFC, com bolsa de Desenvolvimento Científico Regional do CNPq. Atualmente, está associado ao Curso de Pósgraduação em Geologia da UFC como professor visitante (CAPES), onde ministra disciplinas regulares do curso e orienta uma dissertação de mestrado. Seus principais interesses são tectonofísica e geofísica regional e aplicada, a partir da utilização de métodos potenciais e eletromagnéticos. Ele publicou um artigo em revista internacional, apresentou 20 trabalhos em congressos nacionais e internacionais e é membro da Sociedade Brasileira de Geofísica.

\section{Raimundo Mariano Gomes Castelo Branco}

Mariano Castelo Branco é geólogo pela UFC, mestre pela USP e Doutor em geofísica e sensoriamento remoto pela Université de Nantes (França). Desde o início da década de 80 está ligado ao Departamento de Geologia da Universidade Federal do Ceará onde é o responsável pelo Laboratório de Geofísica de Prospecção e Sensoriamento Remoto. Neste período ministrou disciplinas e foi coordenador de diversos projetos de pesquisa ligados à geofísica de prospecção, à geofísica regional, à geologia e geofísica de corpos kimberlíticos e astroblemas, ao sensoriamento remoto e processamento digital de imagens. Entre diversas atividades acadêmicas e de pesquisa registra-se vínculo com o curso de graduação e de pós-graduação em Geologia, notadamente nas linhas de pesquisas afins. Outras atividades envolvem a orientação de dissertações, orientação de bolsistas de DCR/CNPq, AT/CNPq e IC/CNPq. As principais áreas de interesse são a geofísica regional, geofísica de estruturas circulares (kimberlitos, alcalinas, astroblemas) e, sobretudo, a geofísica de prospecção aplicada a água subterrânea envolvendo métodos potenciais, elétricos e eletromagnéticos (ER, VLF, EM, GPR). Sua publicação envolve cerca de 60 resumos, extended abstracts e trabalhos completos em congressos nacionais e internacionais e 12 artigos em revistas com corpo editorial. 